OPEN ACCESS

Edited by:

Arlinda Manuela Dos Santos

Cabral,

Lusophone University, Portugal

Reviewed by:

Jodi Nickel,

Mount Royal University, Canada Jason DeHart,

Appalachian State University,

United States

${ }^{*}$ Correspondence:

Mónica Lourenço

monicalourenco@ua.pt

Specialty section:

This article was submitted to

Teacher Education,

a section of the journal

Frontiers in Education

Received: 09 January 2021

Accepted: 23 March 2021

Published: 14 April 2021

Citation:

Lourenço M (2021) From Caterpillars to Butterflies: Exploring Pre-service Teachers' Transformations While Navigating Global Citizenship Education. Front. Educ. 6:651250

doi: 10.3389/feduc.2021.651250

\section{From Caterpillars to Butterflies: Exploring Pre-service Teachers' Transformations While Navigating Global Citizenship Education}

\author{
Mónica Lourenço* \\ Research Centre on Didactics and Technology in the Education of Trainers, Department of Education and Psychology, \\ University of Aveiro, Aveiro, Portugal
}

Global citizenship education (GCE), which aims to empower learners to become proactive contributors to a more sustainable world, has recently emerged as one of the educational priorities of the 21st century. However, according to recent research, GCE is not yet embedded in teachers' practice in a systematic manner, remaining an optional choice for willing and able teachers. Within this framework, this paper reports on a multiple case study conducted with a group of pre-service teachers (PSTs) in Portugal who were introduced to GCE in the third and final year of an undergraduate degree in Elementary Education. The study aimed to understand whether, how and to what extent the teacher education program contributed to PSTs' professional development. Data consisted of individual reflections written by the PSTs throughout an academic year. These were analyzed thematically using grounded theory to formulate an original framework inspired by the butterfly's metamorphosis. Results show that the experience with GCE was positive in developing PSTs' professional knowledge and in helping them (re)construct their "becoming" teacher identities, albeit to different degrees. Implications of the results for teacher education programs are discussed.

\footnotetext{
Keywords: global citizenship education (GCE), teacher education, pre-service teachers (PSTs), teacher professional development, teacher professional knowledge, teacher identity, sustainable development, multiple case study
}

\section{INTRODUCTION}

International discourse has been devoting increasing attention to global citizenship education (GCE), an innovative educational response to the times of rapid and unprecedented change we are living in (Gaudelli, 2016; Tarozzi and Torres, 2016). Its specific mention in the Global Education First Initiative (United Nations, 2012), launched by the former Secretary General of the United Nations (UN) Ban Ki-moon, and its inclusion in the UN 2030 Agenda for Sustainable Development have elevated GCE to other key policy agendas - access to education and quality education indicating that this is one of the educational priorities of the 21st century.

In this spirit, governments and institutions around the world have begun drafting policy documents and guidelines, often with the support of NGOs, advocating the need to integrate a global perspective in the curriculum to promote students' active engagement and a democratic culture in schools (Oxfam, 2015; UNESCO, 2015; Santamaría-Cárdaba and Lourenço, 2021). 
Despite this, attempts to move GCE from paper to reality are still insufficient. According to the UNESCO's (2020) Global Education Monitoring Report, although some countries report including GCE principles in national policy documents, this is not always supported by curricular change or, more strikingly, by appropriate teacher education measures. As a consequence, GCE is still absent from many classrooms worldwide or dealt with in "softer" terms (Andreotti, 2006).

Academic research has been both explaining and adding to these findings. Recent studies confirm that GCE is not embedded in teachers' and teacher educators' practice in a systematic manner, but rather remains a sporadic occurrence and an optional choice for willing and able teachers (Yemini et al., 2019; Franch, 2020). This is often attributed to conceptual vagueness of global citizenship, propensity to teach national or regional citizenship, curricular insecurity of GCE, and lack of administrative or curricular support (Rapoport, 2010; Lourenço, 2018b). Considering that teachers are the most influential agents of GCE, determining both the ways and the extent to which it is implemented in classrooms, it is fundamental to understand how GCE can be best incorporated into teacher education programs right at pre-service stage, so that teachers can develop the confidence, knowledge and skills necessary to teach these topics effectively and encourage these attributes in their students.

Addressing these concerns and the themes of this special issue, this paper reports on a multiple case study (Stake, 2006) conducted with a group of four pre-service teachers (PSTs) in Portugal, who were introduced to GCE in the third and final year of a degree in Elementary Education. The study aimed at understanding whether, how and to what extent the teacher education program of a course titled Educational Intervention Projects contributed to PSTs' professional development. In particular, the study explores how PSTs perceived and experienced GCE, and the extent to which the teacher education program, which included the development of GCE activities for non-formal education settings, contributed to develop PSTs' professional knowledge and to (re)construct their becoming teacher identities. For that purpose, PSTs' individual reflections written throughout one academic year were collected and analyzed thematically using grounded theory to formulate an original framework inspired by the butterfly's metamorphosis.

Despite increasing attention to teacher education within GCE research, to the author's knowledge this is the first study focusing on exploring PSTs' professional development pathways in the intersection between formal (academic) and non-formal education contexts and using an original visual framework. Besides, the study's relevance can be attributed to its timeliness, given that it was conducted amidst social and political upheaval and increasing debate concerning the introduction of the curricular component of Citizenship and Development in the Portuguese school curriculum. Therefore, the study contributes to the emerging discussion on the preparation of globally competent teachers and students as informed and engaged citizens for a more sustainable world.

The article is organized in the following way. It begins with a brief discussion of the notion and relevance of GCE, focusing on its contribution to achieving sustainable development goals, the theme of this special issue. This is followed by a review of key literature and recent research on teacher education and GCE. Then, the study is described, namely the participants and the methodological procedures that were used for data collection and analysis. The following section presents the results of the study focusing on an in-depth analysis of individual cases. The chapter ends with a discussion of the main findings and with concluding remarks that stress the relevance of the results for PST education and suggest avenues for future research.

\section{EDUCATING GLOBAL CITIZENS FOR A MORE SUSTAINABLE WORLD}

Our rapidly changing world faces constant major challenges. Climate change, war and conflict, displacement and migration, poverty and unemployment, human rights violations have all crossed national borders to become global problems that widen inequalities and can make a lasting impact for decades to come. The COVID-19 pandemic has deepened these inequalities, but it has also made us more aware of the interconnected nature of our world. More than ever, we are faced with a collective responsibility to helping reduce long-lasting economic and societal breaches that threaten our shared humanity, and to healing our "common home" (Pope Francis, 2015). In order to meet these demands, it is essential to strive for transformative forms of education that allow learners to critically understand the multiple social, cultural, economic and political forces that shape their lives; to (re)consider their own identities; to participate in the community at a range of levels, based on principles and values such as social justice, human rights, and intercultural understanding; and to work together to make the world a more equitable and sustainable place than the one they have inherited.

Global citizenship education addresses these calls by empowering learners "to engage and assume active roles, both locally and globally, to face and resolve global challenges and ultimately to become proactive contributors to a more just, peaceful, tolerant, inclusive, secure and sustainable world" (UNESCO, 2014, p. 15). Although defining GCE is not an easy task, as the concept is open to many different (and sometimes conflicting) interpretations (Oxley and Morris, 2013; Pashby et al., 2020) and subject to criticism (Dill, 2013; Jooste and Heleta, 2017; Pais and Costa, 2017), GCE can be best understood as a transformative pedagogy whose purpose is to educate citizens to be autonomous and think critically, so that they can understand the existing social inequalities and act in a committed way seeking to transform society into a more just one (Santamaría-Cárdaba and Lourenço, 2021).

According to the UNESCO (2015), this requires the development of three core conceptual dimensions, which are based on, and include, aspects from three domains of learning: cognitive, socio-emotional and behavioral. These correspond to the four pillars of learning described in the Delors report "Learning: The Treasure Within" (Delors, 1996) - learning to know, learning to do, learning to be, and learning to live 
together. The cognitive dimension of GCE focuses on the knowledge and thinking skills necessary to better understand the world and its complexities. The socio-emotional dimension is related to the values, attitudes and social skills that enable learners to live together with others respectfully and peacefully. Finally, the behavioral dimension is linked to the conduct, performance, practical application and engagement of learners, and to their ability to act responsibly with others at local, national and global levels. Based on these dimensions, the UNESCO (2015) identifies key learning outcomes, which describe the knowledge, skills, values and attitudes that learners can acquire and demonstrate as a result of GCE, as well as key learner attributes. These are: informed and critically literate, socially connected and respectful of diversity, and ethically responsible and engaged.

Oxfam (2015) offers a similar perspective on GCE, defining the "global citizen" as someone who is aware of the wider world and has a sense of their own role as a world citizen; respects and values diversity; has an understanding of how the world works; is passionately committed to social justice; participates in the community at local and global levels; works with others to make the world a more equitable and sustainable place; and takes responsibility for their actions. Aspirational global citizens, therefore, transcend national borders, and exert agency on behalf of the global good; they are both critical of themselves and responsive to others; and they are aware of global issues and use this knowledge to assist them in taking action (Koyama, 2015). Educating global citizens is, then, to provide learners of all ages and backgrounds with relevant opportunities to help them understand who they are in the world and make informed decisions in an increasingly interconnect and multicultural world.

Although GCE has been the focus of international, regional and national conferences, fora and workshops since the 1990s, momentum around this educational perspective has increased since 2012. In September of that year, Ban Ki-moon launched the Global Education First Initiative (GEFI) to accelerate progress toward the Education for All Goals and the Millennium Development Goals. GEFI had three priorities: (1) to ensure every child is in school; (2) to improve the quality of learning; and (3) to foster global citizenship. In order to help the nations of the world meet these priorities, the document also identified 10 key actions, three of them specifically addressing GCE:

- To develop the values, knowledge and skills necessary for peace, tolerance, and respect for diversity.

- To cultivate a sense of community and active participation in giving back to society.

- To ensure schools are free of all forms of discrimination, including gender inequality, bullying, violence, xenophobia, and exploitation.

The adoption of the Sustainable Development Goals (SDGs) at the UN Sustainable Development Summit and of the Education 2030 Framework for Action at UNESCO's General Conference in 2015 provided another major impetus to GCE. SDG Target 4.7 focuses specifically on the transformative potential of GCE in building peaceful and sustainable societies, highlighting the following:

By 2030, ensure that all learners acquire the knowledge and skills needed to promote sustainable development including, among others, through education for sustainable development and sustainable lifestyles, human rights, gender equality, promotion of a culture of peace and non-violence, global citizenship and appreciation of cultural diversity and of culture's contribution to sustainable development (United Nations, 2015).

Global citizenship education, therefore, plays a crucial role in the realization of the 2030 Agenda. The four areas of sustainability - economic growth, social inclusion, governance and environmental protection - rely on the contribution of global and informed citizens. This makes SDG 4.7 the most critical and ambitious education targets, both in its own right and in its potential to reinforce progress in many (if not all other) SDGs, constituting "the very heart of the sustainability agenda" (King, 2017, p. 808).

In direct response to the above calls to mainstream GCE as a possibility to educate citizens to build a more sustainable world, governments around the world have been including GCE in their education policy documents and curricula, yet with different emphasis between countries as a result of diverse socio-economic, political and historical contexts. For instance, across Europe, GCE has become increasingly popular framed by the growing displacement of people fleeing violence and environmental disaster across European borders, a rise in rightwing populism across the continent and the threat of terror and radicalization (Tarozzi and Mallon, 2019). Nonetheless, the latest reports on progress toward meeting target 4.7 have concluded that worldwide GCE levels remain low. According to UNESCO's (2020) Global Education Monitoring Report, only 12\% of countries report including GCE and sustainable development principles in national policy documents and curricula. About 8 in 10 countries report revising textbooks, although changes are constrained by the slow progress of curricular reform and textbook development. Most striking is the fact that appropriate teacher education measures are lacking, such as effective professional development opportunities and support to introduce GCE. Indeed, in many countries pre-service and in-service teacher programs include limited or no core knowledge in this field. As highlighted by Hopkins (2020, p. xxiii),

to many of the world almost 90 million teachers at all levels of education, this concept is still unknow or perplexing. With 69 million additional teachers needed to achieve the education goals of 2030 Agenda for Sustainable Development, GCE is one of the most crucial concepts to understand and to apply in the classroom in order to deliver quality education for students.

This means that pre-service and on-going teacher education is fundamental to ensure teachers possess the required 
subject knowledge and confidence to teach for and about global citizenship.

\section{TEACHER EDUCATION FOR AND ABOUT GLOBAL CITIZENSHIP}

As noted by several authors (Goren and Yemini, 2017; Yemini et al., 2019; Estellés and Fischman, 2020), GCE is an emerging topic in teacher education literature. Researchers have examined pre-service and in-service teachers' beliefs and knowledge of GCE (Holden and Hicks, 2007; Rapoport, 2010); in-service teachers' practices and signature pedagogies in teaching for global citizenship (Tichnor-Wagner et al., 2016); and the impact of GCE-oriented professional development programs for PSTs (Appleyard and McLean, 2011; Guo, 2014; An, 2014; Patrick et al., 2014; Kopish, 2017; Andrade and Lourenço, 2019) and teacher educators (Blanks, 2013; Lourenço, 2018a,b).

One of the earliest studies to investigate the knowledge and understanding that PSTs have of global issues, and their motivation to include a global dimension in their teaching was conducted by Holden and Hicks (2007). The study used both quantitative and qualitative methods for data collection, such as questionnaires to a total 856 students from four universities across the southwest of England and in-depth interviews to a selected sample of 41 . Findings revealed that PSTs wished to know more about global issues and felt they could make a difference to pupils' understanding of those issues. Yet, some expressed a lack of confidence in teaching for global citizenship. As the authors explained "global issues are seen as sensitive, controversial and complex and they feel they need specific guidance on appropriate teaching methods and better subject knowledge" (Holden and Hicks, 2007, p. 22).

Similar results were reported by Rapoport (2010) with in-service teachers in the United States. The article, suggestively titled "We cannot teach what we don't know," investigated how Indiana teachers conceptualize global citizenship, what pedagogies and sources they use to provide international and global frameworks in their instruction, and what in their opinion is impeding the introduction of GCE in schools. Based on data collected through indepth interviews with six secondary teachers, the study shows that teachers were generally positive toward GCE, but they lacked the confidence needed to bring it into their classroom practices, demanding rigorous methodological, content, and curricular assistance to teach emerging types of citizenship.

These studies clearly indicate that pre-service and inservice teachers, even those who are genuinely committed to teaching from a global perspective, need clear and straightforward theoretical and methodological support to justify their initial interest in teaching about global citizenship. The absence of such support and of unambiguous curricular guidance may undermine teachers' motivation to integrate GCE into their professional practice and to engage students in this endeavor. Considering these results, it is not surprising that most articles addressing GCE and teacher education in recent years have focused on proposing and investigating the impact of GCE-oriented professional development programs.

Global citizenship education places considerable professional development demands on teachers to master its practices and to be sensitive to its tensions and complexities, as well as to its benefits and potentials (Guo, 2014). GCE requires both curriculum and personal transformation. If today's "ideal citizen" is interculturally competent, socially responsible, and globally aware, the "ideal educator" should also learn from and engage with others, participating in the community at a range of levels. Zeichner (2010) and Zhao (2010) have identified some of the necessary dispositions, attitudes, knowledge and skills to teach in globally competent ways. These include such things as knowledge and understanding of the international dimensions of teaching and a range of global issues; foreign language proficiency and a deep understanding of other cultures; pedagogical knowledge and skills to educate students from diverse backgrounds and to help them acknowledge multiple points of view; ability to develop local, national and international partnerships; intellectual curiosity and problemsolving skills; and a commitment to assisting students to become responsible citizens both of the world and of their own communities.

These competences are not sufficiently developed in teacher education programs (O'Connor and Zeichner, 2011; Kopish, 2017). In part, this is due to the fact that teacher education is still widely considered a matter of national interest, an attitude that goes back to the construction of nation-states and the creation of education systems in the eighteenth and nineteenth centuries. Thus, many teacher education programs still focus on preparing teachers to impart knowledge about methods and procedures that are appropriate to local contexts and standardized groups, and that aim to foster nationalist feelings of belonging.

In order to counter this state of affairs, and provide teachers, particularly pre-service, with strong preparation and appropriate learning opportunities to develop the knowledge and pedagogies to engage in GCE with their future students, several teacher educators have been sharing their experiences and ideas to support teacher professional development. Marshall (2007) recommends that teacher professional development programs help teachers engage with the participatory pedagogy of GCE; understand how to integrate GCE within and across mainstream curricula; and learn how to practice GCE outside the classroom (inviting outside visitors, organizing global days, events, assemblies or exchanges). Appleyard and McLean (2011), on their part, suggest that best practices for professional development in GCE should include consistent use of pedagogies such as experiential learning and explicit modeling; targeted instruction in specific intellectual, affective, and action domains of GCE; opportunities to practice and reflect on the implementation of GCE in classroom settings; and develop collaborative networks of support. Other teacher educators have defended the use of simulations (Myers and Rivero, 2019), drama (Blanks, 2013), (international) service-learning 
(Larsen and Searle, 2017), and cross-cultural communication (Kopish, 2017).

In general, professional development programs aimed at preparing teachers for GCE have been shown to impact their predispositions toward this educational perspective and to develop their understanding of this field. Patrick et al. (2014) concluded that the integration of GCE in undergraduate courses of future primary and secondary school teachers contributed to the development of knowledge on global issues, methodologies and resources, allowing teachers to understand the relevance of this approach to the education of their students. An (2014) found that a social studies methods course that used a transformative approach was effective in helping candidates to develop conceptual lenses of GCE and to begin building confidence in their teaching as global citizenship educators. More recently, Andrade and Lourenço (2019) shared how a PST developed professional knowledge and reconstructed his professional identity, while designing, implementing and evaluating a project on GCE for primary school children.

In line with the above research, the study reported in this article attempts to unveil PSTs' professional development pathways while taking part in an undergraduate course titled Educational Intervention Projects, which introduced them to GCE. In particular, it explores PSTs' discursive repositioning as an indicator of the development of their professional knowledge (about education in general, about GCE and its methodologies, and about the curriculum), and professional identity, i.e., how teachers see and understand their work and their place in a global world.

\section{THE STUDY}

\section{Background: GCE in Portugal}

In Portugal GCE has gained momentum in recent years, not only as a response to international calls to educate critical and responsible citizens, but also as a result of a political openness to integrate citizenship issues in the curriculum. According to a review of the GCE literature published in the last 10 years in six different languages (Academic Network on Global Education and Learning, 2020), the number of articles, chapters and thesis in the Portuguese context has risen sharply since 2015. The expansion of the field is also evident in scientific events that have started to include GCE as a strand, as well as in the range of resources and guides that teachers have at their disposal to bring GCE into the classroom (see, for instance, Neves and Coelho, 2018).

The first time the expression GCE appeared in national policy documents was in 2010 within the National Strategy for Development Education (2010-2015). The Strategy states as its main goal "to promote global citizenship by raising awareness of the Portuguese society to development issues in a context of growing interdependence and acting toward social transformation" (Instituto Português de Apoio ao Desenvolvimento, 2009, p. 28). In 2017, within the scope of the Project for Autonomy and Curriculum Flexibility in schools, and in line with the document Students' Profile at the End of Compulsory Schooling, the Portuguese government approved a National Strategy for Citizenship Education, which aims to develop competences for a culture of democracy with an impact on individual civic attitudes, interpersonal interactions, and social and intercultural relationships. This document instituted the curricular component of Citizenship and Development as a cross-curricular or stand-alone subject at all levels and cycles of compulsory education. This measure, which in theory opened the door for the integration of GCE in the curriculum, was met with some distrust from teachers and criticism from conservative sectors of the Portuguese society. While the first expressed difficulty in managing these demanding changes, both in terms of preparation to work in this field, and in terms of its transversal and cross-curricular nature, which is uncommon in Portuguese schools; the latter issued a manifesto defending the possibility of conscientious objection, considering that the curricular component might undermine religious education and promote secular values.

This context presents itself as an opportunity for broad debate and discussion about GCE, its principles, values, methodologies and teacher preparation, which might help overcome resistance caused by misinformation and different worldviews.

\section{The Teacher Education Program}

The context for this study was a 28-week compulsory course titled Educational Intervention Projects, which is part of the third and final year of an undergraduate study program in Elementary Education of a Portuguese Higher Education Institution. This degree is followed by a Master's in Teaching, with the duration of three to four semesters, which is a requirement for teaching in Portugal and includes teaching practicum. Students who take this degree can choose one of the following master's degrees: Pre-Primary and Primary Education; Primary Education and Teaching of Portuguese, History and Geography in Elementary Education; or Primary Education and Teaching of Mathematics and Natural Sciences in Elementary Education.

In Educational Intervention Projects students are organized in small working groups (of two to four people) and must choose a preferential theme/area to develop their intervention projects (e.g., intercultural education, global citizenship, outdoor learning in the early years, physical education, science education. . .). Each group is then assigned a mentor and a formal or non-formal education context where they are expected to implement their project. The basic structure of the course is similar across all areas: in the first semester, students conduct observations in three different educational settings and write both individual reflections and group reports detailing and analyzing their experiences; in the second semester, students design, implement and assess an intervention project in one of those settings.

In the academic year 2019/2020, the teaching program that focused on GCE followed this generic structure and aimed to assist a group of four PSTs in developing the concepts, approaches, and related confidence to become global citizenship educators. With this goal in mind, the following activities were conducted by the PSTs: 
- visiting and observing three settings - a primary school, a social security institution aimed for children with special education needs, and the educational services of a nearby municipality

- attending lectures on GCE and related themes

- reading and discussing key literature on GCE

- designing GCE activities for eight non-formal education settings aligned with the Portuguese primary school curriculum

- participating in 2-h weekly discussions with the mentor

- writing individual reflections and group reports

Due to the Coronavirus lockdown, imposed by the Portuguese government after 18 March 2020, two major adjustments were made to the initial structure of the course. Firstly, the 2-h weekly discussions moved to an online format via Zoom, and a WhatsApp group was created to enable swifter feedback and the exchange of useful links and ideas for GCE practice. This opened the door for honest conversations about beliefs, concerns, and questions related to GCE, allowing the group and the mentor to maintain a sense of community. The second major change was related to the impossibility to implement the activities in the non-formal settings and with groups of children. For that reason, instead of an intervention project, PSTs created a book with GCE activities, focusing on topics such as globalization and interdependence, linguistic and cultural diversity, and sustainability. These proposals were simultaneously designed to fit the Portuguese curriculum for primary school and the characteristics of eight municipal non-formal education settings: a cultural center, a documentation center, an environmental education center, a library, a maritime museum, a road safety education center, a science center, and a ship museum.

Pre-service teachers' evaluation instruments consisted of a group report conducted after the first semester, lesson plans and resources on GCE created for the book, and five individual reflections written at significant moments during the course. Only the latter are analyzed for this study.

\section{Participants}

Participants in this study were a group of four PSTs - Chloe, Irina, Laura and Martha ${ }^{1}$ - who chose GCE as a preferential theme to develop a project within the course Educational Intervention Projects. Despite the fact that the participants were representative of today's typical beginning elementary teachers, in that they were female, White, and mainly in their early 20s, they were diverse in both their education and experience. Chloe, 31 years old, was the oldest of the group. She had a previous degree in Information and Communications Technology (ICT) and some working experience in advertising photography. Irina, 20, had a professional course as a wind-instrumentalist. In parallel to her studies, she played in a band and taught Music to young children. Laura, 19, had a similar background to Irina and had been teaching Music to 5 to 14-year-old learners for five years. Only Martha, 19, had no prior teaching experience and had chosen this degree as a second option, although she was now fully

\footnotetext{
${ }^{1}$ To maintain anonymity, pre-service teachers' names are pseudonyms.
}

at peace with her decision. None of the four students had had any training on GCE and this was the first time they were hearing about this transformative form of education.

\section{Aims, Research Design, and Methodological Procedures}

As previously stated, this study aimed at understanding whether, how and to what extent the teacher education program of a course titled Educational Intervention Projects contributed to PST's professional development on GCE. In line with this aim, three specific objectives were defined:

- To explore how PSTs perceived and experienced GCE.

- To identify changes in PSTs' professional knowledge and teaching identities resulting from the teacher education program.

- To identify PSTs' pathways toward globally competent teaching.

To address these objectives, a qualitative multiple case study was developed (Stake, 2006) and each PST's experience viewed as a single case. This allowed the researcher to understand differences and similarities between the cases and develop thick descriptions of PSTs' individual pathways that could inform theory.

\section{Data Collection}

Data collected for this study consisted of five individual reflections (IR) written by the PSTs throughout one academic year (from October 2019 to June 2020). Reflective writing has been shown to enable individuals to tap into knowledge gained through experiences, to develop critical analysis, to contribute to unique connections being made between disparate sets of information, and to new perspectives being taken on issues. Therefore, it is an essential part of any teacher's professional growth (Schön, 1983; Scanlon et al., 2002). For this study, PSTs' IR were considered content rich texts and appropriate to have access to the professional knowledge developed during the teacher education program, and to identify identity transformations in teachers' thinking regarding their role as GCE teachers. Each IR was written at significant moments during the course and had different foci, as highlighted in Table 1.

\section{Data Analysis and Visual Model}

Pre-service teachers IR were analyzed using both deductive and inductive thematic analysis (Braun and Clarke, 2006). The researcher began by reading and rereading the data to gain familiarity with the content. Then, she made notes on the margins of the texts to highlight emerging themes from individual teachers' cases (e.g., "understanding the relevance of GCE," "bringing GCE to the classroom"). She then returned to the data to refine and reduce these initial themes so that they were aligned with the research objectives (e.g., "pedagogical knowledge on GCE”). Once this step was completed, the researcher used a grounded theory approach (Corbin and Strauss, 2015), which drew on the data and on key GCE literature on globally competent teaching, to develop a visual model that not only illustrated the pathways toward GCE that were evident in the 
TABLE 1 | Suggested topics and dates for pre-service teachers' individual reflections.

\begin{tabular}{|c|c|c|}
\hline Individual reflections & Suggested topics & Dates \\
\hline (1) Who am I? & $\begin{array}{l}\text { Tell me about yourself. How did your academic preparation and experiences contributed to your } \\
\text { decision to become a teacher? What are your expectations regarding this degree/course? }\end{array}$ & October 2019 \\
\hline (2) Me as a GCE teacher & $\begin{array}{l}\text { Imagine yourself as a GCE teacher. What content would you (like to) teach? Which } \\
\text { methodologies/approaches would you use? What would your teaching mission be? }\end{array}$ & November 2019 \\
\hline (3) The first semester experience & $\begin{array}{l}\text { How would you describe your experience during the first semester? Which significant moments would } \\
\text { you like to highlight? What challenges/difficulties did you encounter? How did you overcome them? } \\
\text { What did you learn in relation to GCE? }\end{array}$ & January 2020 \\
\hline (4) Reading about GCE & $\begin{array}{l}\text { What did you learn from reading these texts (about GCE, about education, about the teacher you want } \\
\text { to become)? }\end{array}$ & March 2020 \\
\hline (5) Looking back and moving forward & $\begin{array}{l}\text { How would you describe your experience in this course? Which significant moments would you like to } \\
\text { highlight? What challenges/difficulties did you encounter? How did you overcome them? What did you } \\
\text { learn (about GCE, about education, about the teacher you want to become)? How did the teacher } \\
\text { education program contribute to your personal and professional development? }\end{array}$ & June 2020 \\
\hline
\end{tabular}

data but could also serve as a broad representation of teacher professional development on GCE.

The visual model was grounded on the idea that globally competent teaching is a path rather than an end goal, i.e., "a lifelong process one must reiteratively attend to as the world rapidly changes" (Parkhouse et al., 2016, p. 271). This path is marked by a series of personal and professional transformations that lead to a final metamorphosis. In this sense, it can be depicted by applying the metaphor of the butterfly's metamorphosis, which in Western literature has been associated with countless human transformations.

A butterfly's life cycle includes four stages: egg, caterpillar, chrysalis and butterfly (Figure 1). During "egg time," under the protective shell of the family and/or through contact with their peers and teachers, prospective PSTs go through a series of accumulating experiences that affect how they come to regard teaching, education, and teachers' role in society. These experiences may be broader in nature, including prior experiences as students, or more specific, such as (study) trips, (international) volunteering or service learning, which seem to directly contribute to promote global and intercultural awareness. As a result of (or in spite of) these experiences, the decision to become a teacher takes form (the eggs hatch) leading individuals to enroll in a teacher education program.

In the early years of teacher preparation, PSTs resemble caterpillars - initially they just scrape of the top or under surface of the leaf, but once their jaws have grown stronger and larger, they become voracious feeders, eager to learn and to add to their burgeoning professional knowledge. When faced with a transformative and complex educational paradigm such as GCE, PSTs either reject it or enter a continuous learning process in order to increase subject knowledge and pedagogical knowledge, for instance on GCE themes or on the most appropriate methodologies, approaches and resources to integrate GCE into national curricula. Just like caterpillars, who shed their skin four to five times as their bodies grow, PSTs may also endure distinct stages of growth during caterpillar time, after which they stop feeding and search for a pupation site.

Having had little time for reflection as caterpillars, PSTs on their road toward globally competent teaching need to cover themselves with a cocoon and spend some time as chrysalides. This a period of major transformation that may last weeks, months, or even years. For PSTs this represents a time to mature, to experiment with GCE, to reflect critically on that experience and to (re)construct a professional identity that is committed to GCE and to social change.

Once this happens, PSTs emerge from the chrysalis as butterflies and take to the air in search for "flowers" to feed. It is time for them to take place in front of their own classroom, where they can start touching and inspiring others (their students, peers, and stakeholders), and acting toward social transformation within and beyond their own communities. If a butterfly's cycle is not complete until it lays new eggs, the mission of GCE teachers is not over until they motivate future generations of learners to bring about positive change either as global citizens or educators.

\section{RESULTS}

Results from data analysis are presented as individual vignettes of each case. Statements are illustrated by quotations from PSTs' IR, which were translated from Portuguese into English to reach a broader readership.

\section{Irina: Discovering the Relevance of GCE}

Ever since she was little, Irina dreamed about becoming a teacher. She used to role-play with her cousins and pretend she was teaching young children. However, after finishing high school and successfully completing a professional course as a windinstrumentalist, she started having second thoughts. It was only when she was invited to teach music that she decided to take a degree in Elementary Education. "So far, I can say that I am very happy with my decision and I have no regrets!" (IR1, p. 1), she writes.

After a seminar introducing GCE to the group, Irina wrote her second reflection about the kind of teacher she wanted to become. Her reflection was illustrated by a drawing (Figure 2) portraying a very traditional classroom with tables and chairs arranged in a row, a blackboard with chalk and eraser, and a female teacher taking the lead of the learning process and 


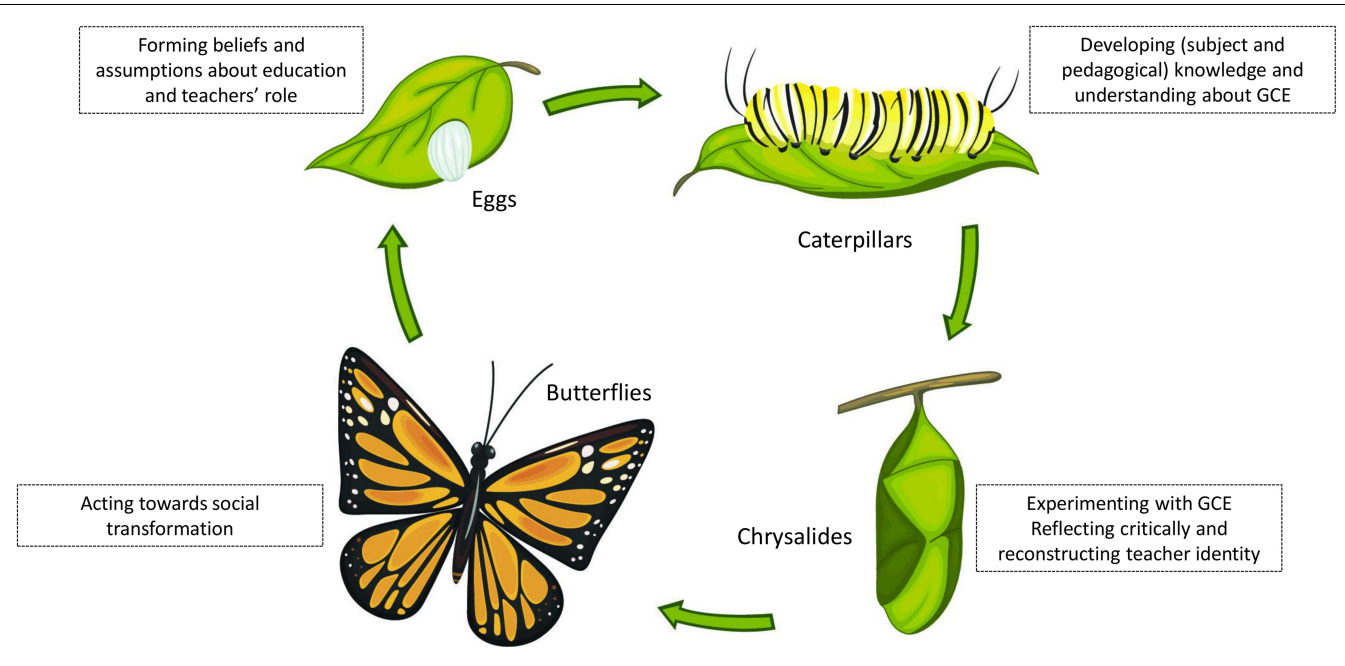

FIGURE 1 | A framework for analyzing PSTs' pathways towards GCE.

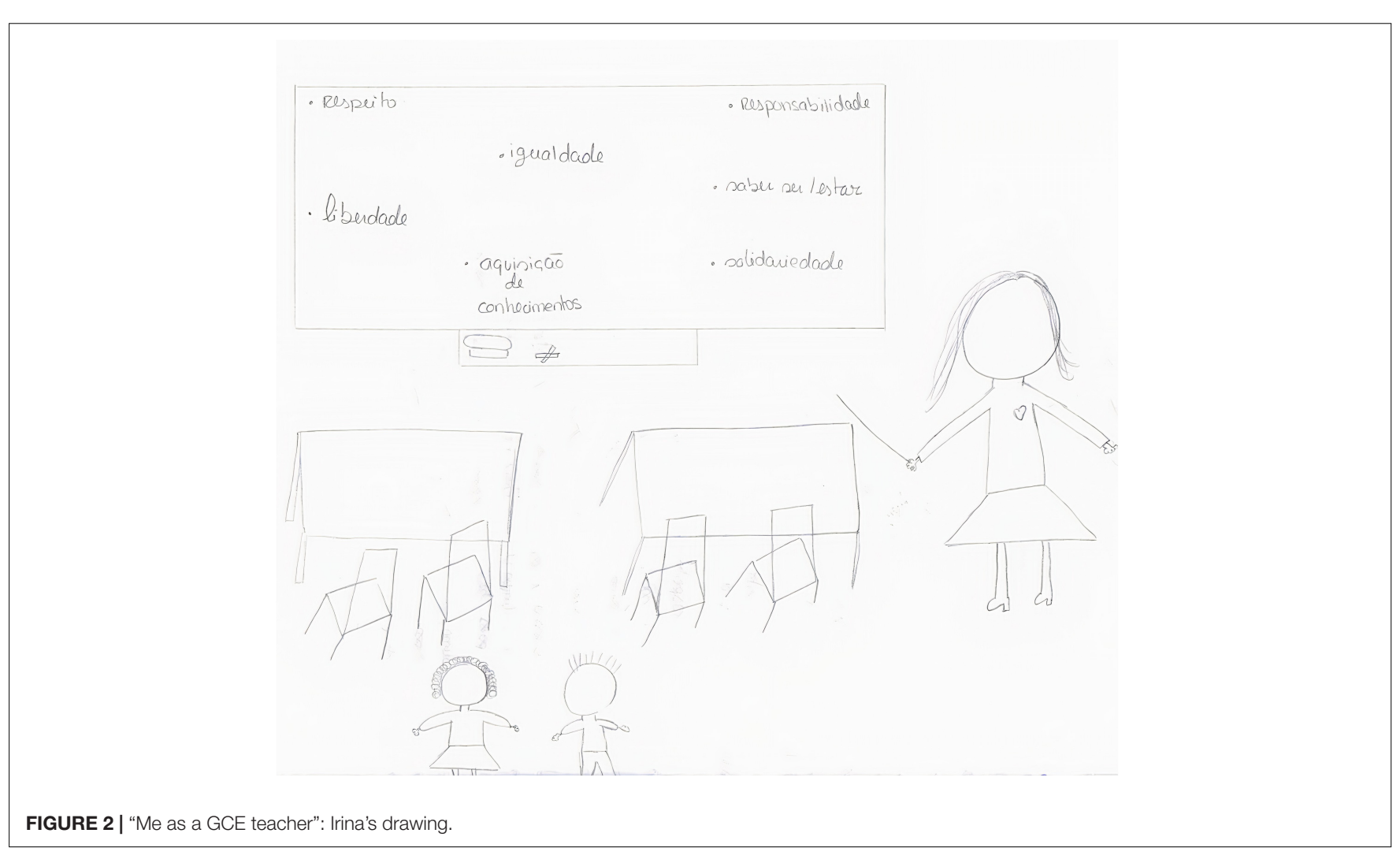

adopting what appears to be a transmissive teaching pedagogy. The only innovative elements in this classroom snapshot were the words written on the board. According to Irina, these represent "the fundamentals" of her teaching - respect, equality, freedom, solidarity, responsibility, learning to be, learning to act and content knowledge.

As a GCE teacher she would like to educate "better human beings" (IR2, p. 1) through teaching key values, and to volunteer abroad in "poor countries with low schooling levels" (ibid.). The link between GCE and values-based education is understandable, as both provide learners with a sense of direction that might help them make informed choices and decisions (see, for instance, Scoffham, 2020). Research has also underlined the link between GCE and international experiences, such as volunteering and study abroad (see, for instance, Killick, 2012; Klein and Wikan, 2019), as these have the potential to develop global awareness and a set of skills and attitudes that allow individuals to engage with global issues and to live 
in multicultural societies. For Irina, volunteering is regarded as an opportunity to "grow as a teacher" (IR2, p. 1) and to "learn from others" (ibid.), suggesting that she is aware that teaching is a lifelong learning process.

The third moment of her reflective writings occurred after the first semester. By that time, the group had been able to visit and observe formal and non-formal education settings. Irina considered the experience in the non-formal settings the most significant one, as it allowed her to become familiar with the educational work that is conducted outside schools and that aims to bring children closer to the community and to their identity roots. This experience, together with the lectures and weekly discussions with the other group members and with the mentor triggered what she considered "a remarkable personal and professional growth" (IR3, p. 2). As she highlights,

I discovered a new way to look at the theme of GCE and at things in general. (...) I feel that I am more attentive to the world around us (...) In the long run, I can see that as a GCE teacher I will pay more attention to my surroundings, I will value global citizenship more, and I will transmit to children that a small gesture can make a difference and really change the world (Irina, IR3, p. 3).

For the reading assignment, which was the background for the fourth reflection, Irina chose an article on teacher professional development for GCE and a book on globalization by Anthony Giddens. Summarizing what she gained from reading those texts, she writes

The role of education in a globalized world is to prepare citizens that are aware of the world around them and understand how the world works, and that respect and value diversity. We, as future teachers, have the responsibility to promote GCE (Irina, IR4, p. 2).

This excerpt shows that Irina understands the educational value of teaching for global citizenship and her responsibility as a teacher. Nonetheless, the use of the personal pronoun "we" instead of "I" may suggest that she has not fully committed to this endeavor.

Her final reflective moment took place in June, after the group had developed a book with pedagogical proposals on GCE for eight non-formal contexts. Reflecting about what she gained from the whole experience, she mentions that the "theme" of GCE "raised issues" and helped her "become more aware" of the need to become a global citizen and a global teacher. She learned that GCE is a current educational perspective that must be valued and known, despite its complexity. As she states, "I felt some difficulties in the theoretical and conceptual part, because this is a complex theme with many subthemes, such as linguistic and cultural diversity or sustainability" (IR5, p. 2). Still, she sees herself as teaching the "theme" of GCE in the future using "creativity to motivate children to pay attention to it" (ibid.) and starting in the early years.

In short, for Irina, the teaching program was important for her to become aware of GCE and of its relevance in a globalized world. She feels motivated to teach for global citizenship in the future, as this educational perspective is aligned with her own vision of teaching for and through values. However, the fact that at the end of the program she still considers GCE a "theme," i.e., an add-on to the curriculum that can be dealt with in a sporadic manner, shows that she has not fully incorporated GCE into her "becoming" professional identity. GCE appears to be another interesting topic to add to her burgeoning professional knowledge, another leaf to feed on as a very hungry caterpillar, while she makes her way to the decisive years of the practicum.

\section{Martha: Connecting GCE With the Curriculum}

In stark contrast to Irina, Martha never wanted to become a teacher. The degree in Elementary Education was not her first choice. Yet, as the years at the university passed, she realized that she really enjoyed the world of education, particularly teaching young children, because "they are more challenging" (IR1, p. 1) and "we have more freedom to teach" (ibid.). One of her teaching goals is to work with less privileged children, because "there is where I feel I could make a difference" (ibid.).

Envisioning her role as a GCE teacher, she mentions that she would "promote respect, solidarity and politeness by teaching children simple gestures such as helping elderly people cross the street, smiling at the supermarket cashier, or saying 'please' and 'thank you"' (IR2, p. 1). She would do this by asking children to make a list of good deeds. This would be followed by an interview to the people involved. Then, children would make an exhibit in a public space (e.g., library, city hall), showing the results of their research to the community. Despite the simplicity of these activities and the narrow conceptualization of GCE (here mostly understood as 'civility'), it is interesting to note some elements that are aligned with this educational perspective - awareness of the local contexts, interaction within and beyond the classroom walls with community members, and project-based learning. This might be related with other courses she took at the university that address these issues, but which do not focus on GCE.

After the first semester, Martha wrote again about the type of teacher she wanted to become:

What I will do is to make children understand that we are all different (...) there is no model of how people should be. The most important thing is to lead children to discover the positive things within those differences and to understand that what defines people are their values (Martha, IR3, p. 2).

This remark seems to be a direct result of the observation experience the group had in a school for children with special needs, and shows that, apart from civility, she has added another important dimension to her conceptualization of GCE valorization and respect for differences.

A big breakthrough in her understanding of the concept and of the possibilities to bring it to the classroom occurred after the reading assignment. Martha chose an article by James Banks on teaching social justice, diversity and citizenship in a global world, and a book with pedagogical proposals that articulate GCE with the Portuguese curriculum. In her individual reflection she explains that after reading the first text her "vision about the meaning and relevance of GCE suffered some changes" (IR4, p. 1). She realized that "global citizenship is as important as other basic skills such as reading, writing and arithmetic" (ibid.) and that "being literate means also to be able to reflect and 
act at a global level" (ibid.). As for the second text, it allowed her to understand that "it is possible, although demanding, to create activities that articulate GCE with the curriculum" (ibid.). Summarizing the relevance of the assignment she writes,

The readings and the discussions with the mentor were fundamental to fight some fears and insecurities concerning GCE and to design activities that are articulated with the curriculum and with pupils' ages. They basically allowed me to answer the question: how to connect the themes and practice of GCE? (Martha, IR4, p. 2)

She concludes her reflection by saying that, in the long run, she sees herself developing more activities of this kind, because she now knows it is possible.

In her final reflective moment, Martha highlights the main challenges and contributions of the teaching program. She felt that the main constraints were the complexity of GCE, associated with its transversal nature, which "demanded a lot of study and additional readings" (IR5, p. 2). Regarding the contributions, she felt that the course allowed her to:

understand the complementary role that non-formal contexts play in education; the role that teachers must assume as mentors and facilitators; how to plan activities, taking into account the different curricular areas and topics to be addressed; and, finally, the perception of the teacher that I want to become (one who works different curriculum areas in a creative and interconnected way addressing GCE topics) (Martha, IR5, p. 2).

Finding the connections between GCE and the school curriculum was fundamental for Martha to commit to this new educational perspective. The readings she completed were decisive in helping her shed her last caterpillar skin. Therefore, she seems to be ready to enter chrysalis stage, a pondering time when she can seclude herself in the comfort of a cocoon and let GCE slowly enter her teaching identity.

\section{Laura: Teaching for Social Transformation}

At the beginning of her first reflection, Laura explains the reasons for her career choice: "Ever since I was little, I wanted to become a teacher because I want to contribute to the personal and professional development of children, and to change the world of education (I am aware this is utopic!)” (IR1, p. 1). Throughout the years that led her to the university, she became more aware of the personal and professional instability of teachers' lives and of the devaluation of the teaching profession. Nonetheless, she kept her intention to become an elementary school teacher, and to teach children from 6 to 12 .

As a GCE teacher she imagined herself "addressing social issues (such as respect toward others, acceptance, and social transformation through progress and change) in order to educate children to live in society as citizens" (IR2, p. 1). She also added how she wanted to carry out teaching of GCE - by working with real case studies, using simulations, conducting intervention projects in the community, organizing gatherings and debates, as well as volunteering actions. These activities and the inclusion of social transformation as a goal of her teaching suggest that, contrary to Irina and Martha, Laura seems to be more aware of the active role teachers can play as catalysts for change. As she writes, "If we want to create a better society, we need to start with the education of children and educate better children!" (IR2, p. 1).

In the reflection she wrote after the first semester, she addresses her teaching agency once again.

As a result of the weekly discussions, lectures and observations in the different contexts, I was able to build the foundations and collect the tools that allow me to instill in my future students the relevance of inclusion, emancipation, cooperation, respect for others, diversity, and a feeling of shared humanity, and alert them to their role in the social transformation of society, so that, little by little, we witness an Education directed toward change in a global world (Laura, IR3, p. 2).

Yet, the use of verbs such as "instill" and "alert" seems to denote that Laura has not put a transmissive pedagogy aside in her teaching. For her, educating for global citizenship implies that the teacher is the one responsible for telling students how to think, feel and act. This is one of the commons misunderstandings related to GCE - regarding it as ideological indoctrination.

After the reading assignment, though, her vision of GCE and of her role suffered profound changes. She mentions that, before this course, she thought GCE was a narrow topic similar to human rights and sustainability. The analysis of UNESCO's guidelines for GCE and of articles related to teacher education made her realize that GCE is "much broader" (IR4, p. 1), implying "a new perspective on education" (ibid.) and the "responsibility of all teachers regardless of their subject area" (ibid.). She considers that GCE should be included as a cross-curriculum subject in schools and not be left in the sole hands of the Citizenship and Development teacher. For that purpose, she suggests the inclusion of GCE in all teacher education programs, so that teachers learn how to articulate it with their subject areas.

Regarding her professional future, she vows to "take all necessary measures to awaken students' critical thinking, so that they become active and concerned citizens able to find creative and innovative solutions to local and global problems" (IR4, p. 2). This statement shows that Laura has understood that she is not the one to tell students what to believe in or how to behave. Her role is to be a guide that provides students with relevant opportunities and experiences that promote their critical thinking and allow them to construct an internal learning system that will shape their future choices and decision making.

Her final individual reflection reveals that she has taken yet another step toward globally competent teaching.

\begin{abstract}
My duty as a future teacher is to commit to GCE in the classroom, to inspire other teachers to do so, and to contribute to the education of global citizens. But it is also my duty as a citizen to put into practice what I have learned, to become a global citizen and lead by example (Laura, IR5, p. 2).
\end{abstract}

Laura realizes that GCE demands a "whole-of-person" transformation. Teachers cannot switch on their "global-self" during teaching and switch it off once teaching is finished. GCE has to become part of their personal and professional identity and truly embody who they are. 
In short, it seems that during the course, particularly after the reading assignment, Laura entered chrysalis stage. The months that followed presented important opportunities to reflect on the type of teacher she wants to become and on the role of GCE in constructing her teaching identity and agency. She has not fully reached the point when she can leave the cocoon, as she still feels unsure of how things will work in practice. Indeed, one of her biggest regrets is not to have had the chance to implement the GCE activities the group created for the nonformal contexts with children. The practicum is just around the corner offering a chance to experiment with GCE, after which she might be ready to fly.

\section{Chloe: Committing Personally and Professionally to GCE}

Chloe was the oldest of the group. With a 10 -year age difference, and a previous degree and working experience in the area of ICT, she showed great maturity expressed in her ability to voice her opinion and reflect critically on a variety of issues. Naturally, she took on the task of group leader, organizing the working schedule, making appointments, suggesting discussion themes and readings. This clearly set her apart from the rest of the group. In her first reflection, she explained her decision to become an elementary teacher: "The most rewarding experience I ever had, both at personal and professional levels, was to work with children and teenagers. Therefore, I want to acquire the necessary training to become a future teacher" (IR1, p. 1).

Like Irina, she also made a drawing representing the type of GCE teacher she wanted to become (Figure 3) - "a teacher that embraces ALL children with love and understanding and uses different languages to promote linguistic and cultural diversity" (IR2, p. 1). The strategy to achieve these goals is to use "learning workshops," which she defines as spaces and times where/when children can experiment, discover and learn about themselves and about their community. These workshops would focus on hands-on learning, small-group activity, problem solving, and discussions, aiming to promote innovation, the exchange of experiences, reflection, and the construction of knowledge. This is evidently not the transmissive pedagogy that characterized Irina's drawing, showing that, for Chloe, GCE does not rest on the same methods she experienced as a student, but demands innovative and more flexible approaches that develop critical inquiry.

At the end of the first semester, Chloe expressed more clearly the links she found between GCE and her teaching goals:

\footnotetext{
I have developed a personal interest in GCE, which has been increasing as I become more aware of its principles. I feel that it is mandatory to adopt teaching strategies that cater for the inclusion of all students and for equal opportunities, and that promote an awareness that we need to think and act locally to make a difference at a global scale. It is along these lines that I want to act as a future teacher (Chloe, IR3, p. 1).
}

This excerpt shows that Chloe was able to integrate GCE within her teaching identity and is evidently committed to develop global citizenship through education and through her active contribution as a teacher.
In March 2020, at a time when Portugal was entering lockdown due to the COVID-19 pandemic, Chloe wrote her fourth reflection expressing what she had learned from reading and analyzing several books on GCE and its integration in the classroom. Despite the fact that all students wrote their reflections during the same period, Chloe was the only one to make a direct reference to the pandemic situation.

\begin{abstract}
I am writing this reflection at a time when we are all adapting to a situation of great instability due to a pandemic that is spreading across many countries in the world. This situation, which has had a greater or lesser impact on our lives, makes me wonder that it is urgent to bring GCE to everyone. It is crucial that we try to be more and more aware of what is happening around us, assuming an ethically responsible behavior, collaborating, being tolerant, just, peaceful and promoting social transformation, wherever we are and regardless of other people's beliefs and values (Chloe, IR4, p. 1).
\end{abstract}

Chloe seems to have understood the relevance and urgency of educating for global citizenship in a world marked by constant changes and instability, and of teachers' increased responsibility to not only to be informed and aware of current events, but also to act in an ethically responsible manner.

In her final reflection she explains what she gained from the course and what GCE represents in her professional future:

As an Education student, I consider it fundamental to develop skills that will allow me to make decisions regarding the teaching and learning methodologies that I want to put into practice. From my point of view, it is evident that these methodologies should be effective in promoting the personal, social and professional development of the groups of children and teenagers with whom I will work. It is for this reason that it has become clearer that I want these methodologies to be based on GCE (Chloe, IR5, p. 1).

Referring to the course readings she made throughout the year, she mentions how these increased her professional knowledge of the Portuguese curriculum, serving as an "inspiration to overcome disciplinary boundaries on a practical level" (IR5, p. 1). She also presented a mature understanding of GCE, considering it "a new educational paradigm and a path that should be taken in formal and non-formal contexts to prepare children and teenagers to develop social skills and attitudes for future international cooperation and intercultural understanding" (ibid.).

Chloe is also aware that this seemingly unsurmountable task should not rest solely on the shoulders of teachers: "This road should be taken together with the children, their families and the whole community" (IR5, p. 1). Along these lines, she ends her reflection with a poignant statement: "As a future teacher I believe that we cannot change the world alone, but we can help others do this with us!"

Throughout the course, Chloe has not only discovered but embraced GCE with the same open arms she plans to embrace all of her students. GCE resonated in her mind and heart, representing a concrete possibility for action. After reflecting deeply and critically about the teacher she wants to become and the methodologies she will use, she has matured and acquired the necessary strength to break the cocoon. She is now standing still, sitting on the empty shell, waiting for her wings to dry out. Will 


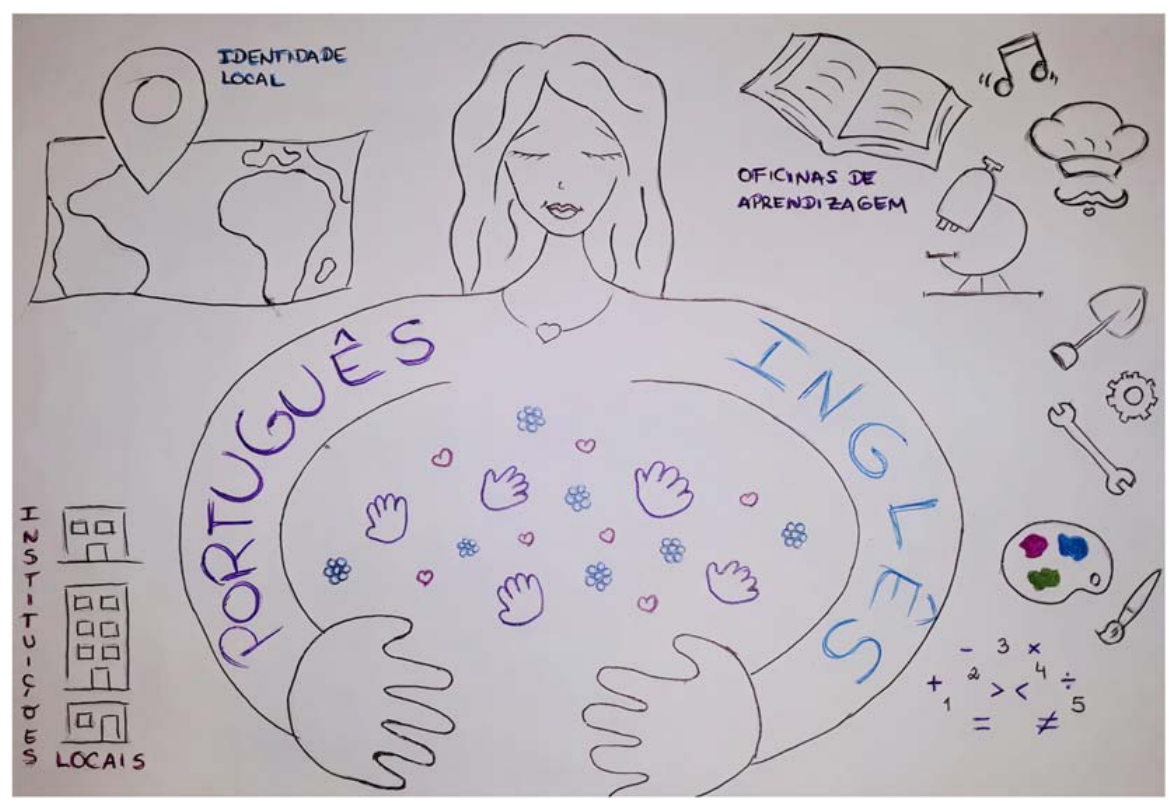

FIGURE 3 | "Me as a GCE teacher": Chloe's drawing.

the practicum allow her to put GCE into practice and emerge as a butterfly, or will she be forced to delay her transformation? As she expresses in her second reflection apropos of the "learning workshop," "these are some ideas that I would like to implement if there is openness in the schools" (IR2, p. 1). Only time will tell if she will be given the appropriate support to make GCE a reality in her teaching and inspire generations to come.

\section{DISCUSSION}

This study aimed at understanding whether, how and to what extent a teacher education program that introduced a group of PSTs to GCE contributed to their professional development. In particular, it sought to explore how PSTs perceived and experienced GCE; to pinpoint changes in their professional knowledge and teaching identities; and to identify their pathways toward globally competent teaching. With these objectives in mind, the researcher collected and analyzed the individual reflections written by four PST throughout one academic year. The following sections focus on discussing the main findings, according to each specific objective and in the light of prior research, and on examining their implications for teacher education programs. This is followed by an analysis of the main limitations of the study and the identification of avenues for future research.

\section{The Main Findings}

\section{Perceptions and Experiences of GCE}

Prior to taking the course Educational Intervention Projects, none of the PSTs had ever heard about GCE. Therefore, it is not surprising that their earlier conceptualizations were quite simple and narrow. PSTs related GCE with civics and values education, and, after the first semester, with inclusion and respect for diversity, as a direct result of the observation experience in a school for children with special education needs.

As the year progressed and the PSTs engaged in other course activities, particularly in the readings and weekly discussions, their conceptualizations of GCE became richer, clearer, and more reflective. Although not all of the PSTs made the same breakthroughs, in their final reflections they showed new perspectives on GCE. For Irina, GCE became a "theme" that should be addressed in today's globalized world, Martha regarded it as a key component of being literate, while Laura defined it as a "new perspective on education." The most mature definition was provided by Chloe who described GCE as "a new educational paradigm and a path that should be taken in formal and nonformal contexts to prepare children and teenagers to develop social skills and attitudes for future international cooperation and intercultural understanding" (IR5, p. 1).

These results are aligned with prior research, which has also reported an evolution in pre-service and in-service teachers' understandings of GCE, as a result of professional development activities such as readings of key literature, concept maps, simulation assignments or construction of resources and lesson plans (see, for instance, An, 2014; Guo, 2014; Myers and Rivero, 2019). These activities, when appropriately framed and provided with enough room for discussion and reflection, seem to allow PSTs to overcome the conceptual complexity they often identify in GCE which prevents them from committing more fully to this transformative form of education.

\section{Pre-service Teachers' Professional Knowledge and Identity}

In light of the results and similar to research conducted elsewhere (see, for instance, Andrade and Lourenço, 2019), the experience 
with GCE appears to have been positive in promoting PSTs' professional knowledge and in helping them (re)construct their teaching identity. Concerning professional knowledge, PSTs developed subject knowledge related to the themes of global citizenship, namely the ones that were at the heart of the activities they designed - linguistic and cultural diversity, sustainability, and globalization and interdependence. Moreover, they increased their pedagogical knowledge concerning GCE methodologies. In this respect, they highlighted the need to use innovative and hands-on approaches (such as experiential learning) that are student-centered, promote critical thinking and move beyond the classroom walls.

Another important learning achievement was increased knowledge and understanding of the Portuguese education policy documents and curricula, particularly for primary school. PSTs mentioned that they learned how to meaningfully embed GCE in the curriculum; how to manage the curriculum in a more flexible way, overcoming subject boundaries; and how to design activities and define learning outcomes that are appropriate to a specific age group. Similar results were reported by the PSTs in Patrick et al.'s (2014) study, who stated they had learned how to teach GCE-focused lessons and how to integrate GCE themes in units of work and programs. Also Guo's (2014) teacher candidates, who had the opportunity to develop lesson and/or work plans based on GCE principles, reported that these hands-on learning-toteach opportunities empowered them to develop professional competences to lead learning for citizenship at the local, national and global levels, while answering to mandated outcomes in the K-12 curriculum.

Although the pandemic situation prevented PSTs from connecting more deeply with the people and spaces of the non-formal education settings, all of them mentioned a heightened awareness of the pedagogical possibilities of those settings in nurturing global citizenship. As they revealed in their individual reflections, non-formal education settings allow learning to become more meaningful for children and articulated with their own reality, thus strengthening their sense of belonging and engagement.

In what concerns teacher identity, the teacher education program played an important role in helping PSTs understand the major purposes of education and, consequently, to (re)consider the demands of the teaching activity in a globalized world. For Irina, the course allowed her to move away from a traditional model of education shut within the classroom walls to understand that as a teacher she needs to be attentive to the world around her. For Martha, it helped her perceive the teacher she wants to become - one that articulates different curriculum areas in a creative manner addressing GCE topics such as inclusion and respect for diversity. These statements mirror similar ones expressed by Guo's PSTs who commented that "GCE allowed for an outlet and impetus to become knowledgeable in global issues and current affairs, and getting creative with the given curriculum" (2014, p. 12).

With respect to Laura and Chloe, the course propelled them to consider their responsibilities more deeply and to think about the necessary coherence between personal and professional self. They realized that GCE requires them to act in an ethically responsible manner and to lead by example to inspire students to change the world. In this respect, they resemble the PST in Andrade and Lourenço's (2019) research, who vowed his willingness to "act as a reference for children," both as a human being and educator, in order to provide children with richer and more appropriate learning opportunities.

Hence, to a greater or lesser extent, GCE resonated in the four PSTs' hearts and minds, and they feel motivated and willing to teach for global citizenship in the future, as this is an education perspective aligned with their own values and beliefs.

\section{Pre-service Teachers' Pathways Toward GCE}

In developing their professional knowledge and identity, PSTs went through a series of stages that were visually represented by the butterfly's life cycle. While most of them started their journey in the course as caterpillars, four different pathways, one for each PST, were identified as the year progressed.

Irina represented the typical teaching candidate who is eager to learn and to become the best possible teacher to help her students succeed and become good citizens. She experienced the course activities as useful opportunities to increase her professional knowledge of the curriculum, of new teaching methods, and of global issues. Yet, at the end of the day, GCE represented just another possibility to choose from when she finally stands before her own groups of students.

As Irina, earlier in the course, Martha presented herself as an eager but somehow insecure caterpillar. Teaching was not her first choice, so she had to see how this new perspective on education could be moved from paper to reality. Once she started to read about GCE, and becoming more acquainted with its principles and methodologies, she soon discovered links with the curriculum, realizing that GCE could be brought successfully to the classroom. This helped her to develop a more committed attitude toward GCE and to slowly make her way to chrysalis stage.

Laura experienced a similar "aha" moment to Martha after the reading assignment. Although her earlier conceptualizations of the teaching profession and of her role as a teacher already shown glimpses of a socially committed attitude, the course allowed her to reflect more profoundly on the type of teacher she wants to become and to (re)construct her teaching identity and agency. From the midpoint of the semester onward, she entered chrysalis stage, a moment to mature, experiment, and reflect critically on experience.

Chloe also experienced similar changes to Laura. Yet, her last reflective writings suggest that she has broken the cocoon and almost left chrysalis stage. GCE represents a concrete possibility for action and she is both personally and professionally committed to it. It should be borne in mind, though, that she is the oldest of the group and already has some working experience, namely teaching learners of different age groups. Still, it was not within the scope of this paper to consider the impact of PSTs' prior experiences on their desire to incorporate global perspectives in their teaching (see Parkhouse et al., 2016), which could be a useful addition for future research. 


\section{Implications for Teacher Education}

Although the goal of this multiple case study was not to generalize its findings, the results discussed above may provide direction not only for this teacher education program but also for other courses. Firstly, the study suggests that some of the activities the PSTs took part in were highly influential in helping them learn how to teach about and for GCE. For instance, the reading assignments were often the basis for making sense of their own experiences and values, and for envisioning their future teaching. It would be important in future courses to broaden the scope of the course readings and to include a list of mandatory texts that go beyond global awareness and "soft GCE," addressing the economic and cultural roots of the inequalities in power and wealth distribution in a global, complex and uncertain system (Andreotti, 2006). This would help PSTs "read" the world critically and consider the "desirable" implications of their teaching agency.

Apart from course readings, other useful strategies to foster PSTs' agency as global citizenship educators is to engage them in hands-on learning-to-teach activities, such as lesson planning and creation of GCE resources. If possible, these could be complemented with implementation in authentic classroom settings and assessment of the results, within an action research methodology. Indeed, action research has been shown to help teachers develop both personally and professionally and acquire an emancipatory perspective about the need to transform themselves and the educational contexts they work in (Cabaroglu, 2014; Lourenço et al., 2018). Future courses could also include GCE-oriented classroom observations by placing PSTs in formal and non-formal settings where they could see GCE in action. This could assure candidates that it is possible to teach about GCE and help them visualize their new identity.

Finally, as Guo states,

a critical element of global citizenship pedagogy is to create an open and safe space where learners are invited to engage critically with their own and, with a diversity of perspectives, to think independently and make informed and responsible decisions based on critical literacy and self-reflexivity (2014, p. 9).

Inviting PSTs to write about and voice their own experiences, fears and anxieties in different moments of a teacher education program on GCE seems fundamental to support their professional development. Another important element is collaboration. In the course, PSTs worked as a group. This provided a support net when they were facing difficulties, which was crucial to help them move forward in the face of adversity, particularly in a year that so vividly embodied the constantly changing and unpredictable nature of our global world.

Altogether, these strategies emphasize the need to simultaneously integrate in teacher education programs activities that focus on the theoretical and conceptual dimension of GCE and on the practical dimension, providing opportunities for PSTs to collaborate with each other and with others (pupils, parents, and community members) in the design, implementation, and assessment of GCE activities.

Yet, this study indicates that a year-long single course is not enough to prepare confident global citizenship educators.
Similar to previous research findings (Holden and Hicks, 2007; An, 2014), although PSTs considered teaching for global citizenship important, they felt unsure about its integration in the curriculum. These results suggest that it is important to create more times and spaces where teachers can learn strategies for teaching about global and controversial issues and improve their own knowledge and understanding. Therefore, as suggested by Laura, it is fundamental to integrate GCE into teacher education programs in a more systematic way throughout PSTs' academic preparation. As postulated by other authors, efforts to prepare teacher candidates for globalized contexts should be a coordinated approach that is integrated across disciplines and in courses and programs for prospective teachers (An, 2014; Patrick et al., 2014; Kopish, 2017). Instead of adding one or two courses addressing global citizenship, making GCE a program-wide mission and integrating it into every component of the program (curriculum, pedagogy, field placement, teacher educators' professional development) may better prepare candidates with the knowledge, skills, commitment, and confidence to teach from a global citizenship perspective.

\section{Limitations of the Study and Future Research Avenues}

This research is not without limitations. The first shortcoming is related to the small scope of the study, which is restricted to the experiences of four PSTs in one course of a Portuguese higher education institution. Those enrolled represent a very small sample of teacher candidates who were motivated to select the course theme and may have had initial "buy-in" to the GCE perspectives, curriculum, and pedagogies enacted.

Secondly, as a qualitative case study conducted by a researcher who was simultaneously the teacher educator responsible for the course, subjectivity and positionality are omnipresent and might have influenced data analysis. Adding to researcher bias, participant bias is also a possibility. Considering that individual reflections were part of course assessment, there was a risk that PSTs wrote their texts in a way they believed corresponded to what the researcher/teacher educator was looking for.

Finally, it should not be forgotten that, although PSTs revealed a better understanding of GCE and showed signs of personal and professional development, that does not necessarily mean that they have become more engaged educators and global citizens, or that the optimism and motivation that the course apparently inspired will last long (Estellés and Fischman, 2020). Longstanding peer and leadership support, as well as continuing professional development on GCE, will be fundamental to ensure that they move forward in their pathways toward globally competent teaching.

In light of the above, it might be worthwhile to conduct a follow-up study of these four teachers during and after practicum. This would contribute to understanding the long run effects of the teacher education program and illuminate areas for improvement.

Another possible avenue for research would be to test the reliability of the butterfly's visual model. This could be conducted 
by applying the model to a broader sample of PSTs from different subject areas, but also by investigating the model's usefulness to analyze both in-service teachers' and teacher educators' professional development for GCE.

\section{CONCLUSION}

Teacher education has evolved and incrementally changed over the years. Still, very few teachers today seem to possess the necessary theoretical understanding and professional skills to effectively engage and enable students to become global citizens. As evidenced in this study, becoming a globally competent teacher is a complex process, requiring a deep personal and professional transformation, a "metamorphosis" that allows teachers to reconceptualize their role as citizens and educators in an uncertain world. This is also a long and bumpy journey teachers need time to gain knowledge and understanding of GCE, to discover its multiple configurations, to find appropriate spaces and methodologies to bring it into the classroom, to experiment, fail and succeed, and to reflect individually and collectively on their own values, prejudices and experiences. The multiple paths taken by these four PSTs suggest that the road toward globally competent teaching is not well marked. There is no straightforward way to make sure that the experience with GCE is influential enough to allow PSTs to gain the necessary knowledge, confidence and skills to educate for global citizenship. Yet, it is our job as teacher educators to keep on trying and to do our best to provide meaningful opportunities that will enrich PSTs' sense of being and potential, equip them with an awareness of the interconnectedness of the modern world and the agency to initiate change. Recalling the words of McKeown and Hopkins (2010, p. 17),

We cannot afford to be complacent and let someone else figure out how to accomplish our goal and then follow their path at a later date. We all have the responsibility to try something new and share the results with others. We have the opportunity to join a learning community of teacher educators around the word who are struggling with the same questions in their own countries.

Sharing of lessons learned, highlighting the promises and challenges of our own teacher education experiences, will be fundamental to our progress preparing "worldminded" educators and redirecting the current trajectory of the future of our planet.

\section{REFERENCES}

Academic Network on Global Education and Learning (2020). Global Education Digest 2020. London: Development Education Research Centre, doi: 10.4324/ 9780429463860

An, S. (2014). Preparing elementary teachers as global citizenship educators. J. Educ. 194, 25-38. doi: 10.1177/002205741419400304

Andrade, A. I., and Lourenço, M. (2019). "Educação para a cidadania global e identidade profissional: um estudo de caso na formação inicial de professores [Education for global citizenship and professional identity: a case study in pre-service teacher education]," in O Professor do Século XXI em Perspetiva Comparada: Transformações e Desafios para a Construção de Sociedades Sustentáveis, ed. N. Fraga (Funchal: Universidade da Madeira), 537-555.

\section{DATA AVAILABILITY STATEMENT}

The raw data supporting the conclusions of this article will be made available by the authors, without undue reservation.

\section{ETHICS STATEMENT}

Ethical review and approval was not required for the study on human participants in accordance with the local legislation and institutional requirements. The patients/participants provided their written informed consent to participate in this study. Written informed consent was obtained from the individual(s) for the publication of any potentially identifiable images or data included in this article.

\section{AUTHOR CONTRIBUTIONS}

The author confirms being the sole contributor of this work and has approved it for publication.

\section{FUNDING}

This work was financially supported by National Funds through FCT - Fundação para a Ciência e a Tecnologia, I.P., under the project UIDB/00194/2020 and in the scope of the framework contract foreseen in the numbers 4,5 , and 6 of the article 23, of the Decree-Law 57/2016, of August 29, changed by Law $57 / 2017$, of July 19.

\section{ACKNOWLEDGMENTS}

The author would like to thank the four pre-service teachers who so willingly participated in this study, sharing their experiences, expectations, doubts and accomplishments with such honesty and passion. A word of recognition is also due to the people responsible for the education services of the Ílhavo Municipality (SEMI), for making this collaborative project possible and for their enduring support.

Andreotti, V. (2006). Soft versus critical global citizenship education. Dev. Educ. Policy Pract. 3, 83-98.

Appleyard, N., and McLean, L. R. (2011). Expecting the exceptional: pre-service professional development in global citizenship education. Int. J. Prog. Educ. 7, 6-32.

Blanks, D. (2013). Nobel women: drama pedagogy for global citizenship education. Glob. Partners Educ. J. 3, 3-21.

Braun, V., and Clarke, V. (2006). Using thematic analysis in psychology. Qual. Res. Psychol. 3, 77-101. doi: 10.1191/1478088706qp063oa

Cabaroglu, N. (2014). Professional development through action research: Impact on self-efficacy. System 44, 79-88. doi: 10.1016/j.system.2014.03.003

Corbin, J., and Strauss, A. (2015). Basics of Qualitative Research: Techniques and Procedures for Developing Grounded Theory, 4th Edn. Thousand Oaks, CA: Sage. 
Delors, J. (1996). Learning: The Treasure Within. Paris: UNESCO.

Dill, J. S. (2013). The Longings and Limits of Global Citizenship Education: The Modern Pedagogy of Schooling in a Cosmopolitan Age. Milton Park: Routledge.

Estellés, M., and Fischman, G. E. (2020). Who needs global citizenship education? A review of the literature on teacher education. J. Teach. Educ. doi: 10.1177/ 0022487120920254 [Epub ahead of print].

Franch, S. (2020). "Reconceptualising citizenship education towards the global, the political and the critical: challenges and perspectives in a Province in Northern Italy," in Teacher Education for Sustainable Development and Global Citizenship: Critical Perspectives on Values, Curriculum and Assessment, ed. P. Bamber (Milton Park: Routledge), 144-155. doi: 10.4324/9780429427 053-13

Gaudelli, W. (2016). Global Citizenship Education: Everyday Transcendence. Abingdon: Routledge.

Goren, H., and Yemini, M. (2017). Citizenship education redefined - A systematic review of empirical studies on global citizenship education. Int. J. Educ. Res. 82, 170-183. doi: 10.1016/j.ijer.2017.02.004

Guo, L. (2014). Preparing teachers to educate for 21st century global citizenship: envisioning and enacting. J. Glob. Citizen. Equity Educ. 4, 1-23. doi: 10.4018/ 978-1-7998-1435-1.ch001

Holden, C., and Hicks, D. (2007). Making global connections: the knowledge, understanding and motivation of trainee teachers. Teach. Teach. Educ. 23, 13-23. doi: $10.1016 /$ j.tate.2006.04.031

Hopkins, C. A. (2020). "Foreword," in Teacher Education for Sustainable Development and Global Citizenship: Critical Perspectives on Values, Curriculum and Assessment, ed. P. Bamber (Milton Park: Routledge). doi: 10.4324/ 9780429427053

Instituto Português de Apoio ao Desenvolvimento (2009). National Strategy for Development Education (2010-2015). Lisbon: IPAD.

Jooste, N., and Heleta, S. (2017). Global citizenship versus globally competent graduates: a critical view from the South. J. Stud. Int. Educ. 21, 39-51. doi: $10.1177 / 1028315316637341$

Killick, D. (2012). Seeing-ourselves-in-the-world: developing global citizenship through international mobility and campus community. J. Stud. Int. Educ. 16, 372-389. doi: 10.1177/1028315311431893

King, K. (2017). Lost in translation? The challenge of translating the global education goal and targets into global indicators. Compare 47, 801-817. doi: 10.1080/03057925.2017.1339263

Klein, J., and Wikan, G. (2019). Teacher education and international practice programmes: reflections on transformative learning and global citizenship. Teach. Teach. Educ. 79, 93-100. doi: 10.1016/j.tate.2018. 12.003

Kopish, M. A. (2017). Global citizenship education and the development of globally competent teacher candidates. J. Int. Soc. Stud. 7, 20-59.

Koyama, J. (2015). The Elusive and Exclusive Global Citizen. Paris: UNESCO.

Larsen, M. A., and Searle, M. J. (2017). International service learning and critical global citizenship: a cross-case study of a Canadian teacher education alternative practicum. Teach. Teach. Educ. 63, 196-205. doi: 10.1016/j.tate.2016. 12.011

Lourenço, M. (2018a). Cidadania global e integração curricular: desafios e oportunidades nas vozes de formadores de professores [Global citizenship and curriculum integration: challenges and opportunities in the voices of teacher educators]. Indagatio Didactica 10, 9-27. doi: 10.34624/id.v10i1. 11361

Lourenço, M. (2018b). Internationalizing teacher education curricula: opportunities for academic staff development. On the Horizon 26, 157-169. doi: 10.1108/OTH-07-2017-0053

Lourenço, M., Andrade, A. I., and Sá, S. (2018). Teachers' voices on language awareness in pre-primary and primary school settings: Implications for teacher education. Lang. Cult. Curricul. 31, 113-127. doi: 10.1080/07908318.2017. 1415924

Marshall, H. (2007). Global education in perspective: fostering a global dimension in an English secondary school. Camb. J. Educ. 37, 355-374. doi: 10.1080/ 03057640701546672

McKeown, R., and Hopkins, C. (2010). "Global citizenship and sustainable development: transformation in the initial education of teachers," in Education in a Global Space: Research and Practice in Initial Teacher Education, eds T.
Wisely, I. Barr, A. Britton, and B. King (Edinburgh: International Development Education Association Scotland).

Myers, J. P., and Rivero, K. (2019). Preparing globally competent preservice teachers: The development of content knowledge, disciplinary skills, and instructional design. Teach. Teach. Educ. 77, 214-225. doi: 10.1016/j.tate.2018. 10.008

Neves, L., and Coelho, L. S. (2018). Global Schools: propostas de integração curricular da Educação para o desenvolvimento e cidadania global no $1 .{ }^{\circ}$ e 2. CEB [Global Schools: Proposals for Integrating Development and Citizenship Education in the Elementary School Curriculum]. Viana do Castelo: ESE.

O'Connor, K., and Zeichner, K. M. (2011). Preparing US teachers for critical global education. Glob. Soc. Educ. 9, 521-536. doi: 10.1080/14767724.2011.605333

Oxfam (2015). Education for Global Citizenship: A Guide for Schools. London: Oxfam.

Oxley, L., and Morris, P. (2013). Global citizenship: a typology for distinguishing its multiple conceptions. Br. J. Educ. Stud. 61, 301-325. doi: 10.1080/00071005. 2013.798393

Pais, A., and Costa, M. (2017). An ideology critique of global citizenship education. Crit. Stud. Educ. 61, 1-16. doi: 10.1080/17508487.2017.1318772

Parkhouse, H., Tichnor-Wagner, A., Cain, J. M., and Glazier, J. (2016). "You don’t have to travel the world": accumulating experiences on the path toward globally competent teaching. Teach. Educ. 27, 267-285. doi: 10.1080/10476210.2015. 1118032

Pashby, K., Costa, M., Stein, S., and Andreotti, V. (2020). A meta-review of typologies of global citizenship education. Comp. Educ. 56, 144-164. doi: 10. 1080/03050068.2020.1723352

Patrick, K. F., Macqueen, S., and Reynolds, R. (2014). Pre-service teacher perspectives on the importance of global education: world and classroom views. Teach. Teach. Theory Pract. 20, 470-482. doi: 10.1080/13540602.2014.88 1639

Pope Francis (2015). Encyclical letter Laudato Si' of the Holy Father Francis on Care for Our Common Home. Vatican: Vatican Press.

Rapoport, A. (2010). We cannot teach what we don't know: Indiana teachers talk about global citizenship education. Educ. Citizen. Soc. Just. 5, 179-190. doi: $10.1177 / 1746197910382256$

Santamaría-Cárdaba, N., and Lourenço, M. (2021). Global citizenship education in primary school: a comparative analysis of education policy documents in Portugal and Spain. Iberoam. J. Dev. Stud. doi: 10.26754/ojs_ried/ijds.585 [Epub ahead of print].

Scanlon, J. M., Care, W. D., and Udod, S. (2002). Unravelling the unknowns of reflection in classroom teaching. J. Adv. Nurs. 38, 136-143. doi: 10.1046/j.13652648.2002.02157.x

Schön, D. (1983). The Reflective Practitioner. New York, NY: Temple Smith.

Scoffham, S. (2020). "In search of core values," in Teacher Education for Sustainable Development and Global Citizenship: Critical Perspectives on Values, Curriculum and Assessment, ed. P. Bamber (Abingdon: Routledge), 23-31. doi: 10.4324/ 9780429427053-2

Stake, R. E. (2006). Multiple Case Study Analysis. New York, NY: The Guilford Press.

Tarozzi, M., and Mallon, B. (2019). Educating teachers towards global citizenship: a comparative study in four European countries. Lond. Rev. Educ. 17, 112-125. doi: 10.18546/LRE.17.2.02

Tarozzi, M., and Torres, C. M. (2016). Global Citizenship Education and the Crises of Multiculturalism: Comparative Perspectives. London: Bloomsbury Academic.

Tichnor-Wagner, A., Parkhouse, H., Glazier, J., and Cain, J. M. (2016). Expanding approaches to teaching for diversity and justice in K-12 education: fostering global citizenship across the content areas. Educ. Policy Anal. Arch. 24, 1-31. doi: $10.14507 /$ epaa. 24.2138

UNESCO (2014). Global Citizenship Education: Preparing Learners for the Challenges of the Twenty-First Century. Paris: UNESCO.

UNESCO (2015). Global Citizenship Education: Topics and Learning Objectives. Paris: UNESCO.

UNESCO (2020). Global Education Monitoring Report 2020. Inclusion and Education: All Means All. Paris: UNESCO.

United Nations (2012). Global Education First Initiative. New York, NY: United Nations. 
United Nations (2015). Transforming Our World: The 2030 Agenda for Sustainable Development. New York, NY: United Nations.

Yemini, M., Tibbitts, F., and Goren, H. (2019). Trends and caveats: review of literature on global citizenship education in teacher training. Teach. Teach. Educ. 77, 77-89. doi: 10.1016/j.tate.2018.09.014

Zeichner, K. M. (2010). Preparing Globally Competent Teachers: A U.S. Perspective. In Colloquium on Internationalizing Teacher Education Curriculum. Washington, DC: NAFSA.

Zhao, Y. (2010). Preparing globally competent teachers: a new imperative for teacher education. J. Teach. Educ. 61, 422-431. doi: 10.1177/0022487110375802
Conflict of Interest: The author declares that the research was conducted in the absence of any commercial or financial relationships that could be construed as a potential conflict of interest.

Copyright (C) 2021 Lourenço. This is an open-access article distributed under the terms of the Creative Commons Attribution License (CC BY). The use, distribution or reproduction in other forums is permitted, provided the original author(s) and the copyright owner(s) are credited and that the original publication in this journal is cited, in accordance with accepted academic practice. No use, distribution or reproduction is permitted which does not comply with these terms. 